\title{
Drug use disorder and risk of incident and fatal prostate cancer among Swedish men: a nationwide epidemiological study
}

\author{
Disa Dahlman ${ }^{1} \cdot{\text { Xinjun } \mathrm{Li}^{1} \cdot \text { Casey } \text { Crump }^{2} \cdot \text { Jan Sundquist }}^{1,2,3} \cdot$ Kristina Sundquist $^{1,2,3}$
}

Received: 10 March 2021 / Accepted: 15 October 2021 / Published online: 7 November 2021

(c) The Author(s) 2021

\begin{abstract}
Purpose Prostate cancer is the second most common cancer in men and a leading cause of cancer mortality worldwide. Men with drug use disorders (DUD) may potentially be at high risk for prostate cancer mortality because of delayed diagnosis and/ or undertreatment. In this study, we aimed to investigate prostate cancer incidence, mortality, and stage at time of diagnosis among men with DUD compared to the general male population in Sweden.

Methods We performed a follow-up study based on Swedish national register data for the period January 1997-December 2016. The study was based on 1,361,532 men aged 50-75 years at inclusion, of whom 9,259 were registered with DUD. Cox regression analysis was used to compute adjusted hazard ratios (HRs) for incident and fatal prostate cancer, and cancer stage at time of diagnosis, associated with DUD.

Results DUD was associated with a slightly increased risk of incident prostate cancer (HR: $1.07,95 \%$ confidence interval [CI] $1.00-1.14, p=0.048$ ) and substantially higher risk of fatal prostate cancer (HR: $1.59,95 \%$ CI 1.40-1.82, $p<0.001$ ), adjusted for age, socioeconomic factors, and comorbidities related to tobacco smoking and alcohol use disorder. No association was found between DUD and prostate cancer stage at diagnosis.

Conclusions Men with DUD have an increased risk of fatal prostate cancer, possibly related to undertreatment in this patient population. Our findings should raise attention among medical staff and decision-makers towards a disadvantaged group of men in need of easily accessible prostate cancer evaluation and treatment.
\end{abstract}

Keywords Prostate cancer $\cdot$ Drug abuse $\cdot$ Mortality $\cdot$ Sweden $\cdot$ Epidemiology

\section{Introduction}

Prostate cancer is the second most common cancer in men and a leading cause of cancer mortality worldwide [1,2]. Men with drug use disorder (DUD) may have a higher risk of prostate cancer incidence and mortality because of delayed diagnosis and/or undertreatment. This issue has rarely been

Disa Dahlman

disa.dahlman@med.lu.se

1 Center for Primary Health Care Research, Department of Clinical Sciences, Lund University/Region Skåne, Malmö, Sweden

2 Departments of Family Medicine and Community Health and of Population Health Science and Policy, Icahn School of Medicine at Mount Sinai, New York City, NY, USA

3 Center for Community-Based Healthcare Research and Education (CoHRE), School of Medicine, Shimane University, Matsue, Japan examined and is important because DUD has been associated with a range of adverse health outcomes including drug-related [3, 4] and non-drug-related mortality [4-7], breast cancer incidence and mortality [7], blood-borne infections [8,9], and liver disease [10]. The substantial physical morbidity associated with DUD may be partially related to healthcare seeking barriers [11-13], poor health literacy [14], psychiatric comorbidity [15-17], and under-utilization of cancer screening [18-21].

The health risks among people with DUD may further be affected by low socioeconomic status (SES). Several SES factors, for example neighborhood deprivation, being unmarried, or having low income or educational attainment, have been associated with increased prostate cancer risk and worse prostate cancer prognosis [22]. Lifestyle factors such as tobacco smoking and negative alcohol-related consequences are overrepresented among people with low SES [23, 24] or DUD [25-29], and are also identified as 
risk factors for prostate cancer and poor prognosis in some studies although the associations are heterogeneous [30-32].

It is thus possible that men with DUD have a delayed diagnosis and higher mortality in common cancers, including prostate cancer, which is the second most commonly diagnosed cancer among men globally [1]. In Sweden, a country with tax-financed healthcare that is strongly subsidized for the individual [33], prostate cancer is the most common cancer among men with approximately 10,000 men being diagnosed annually [34]. There is no national screening program for prostate cancer in Sweden. Nevertheless, approximately half of the Swedish male population age 50-70 have had a prostate specific antigen (PSA) test, which is offered free of charge to men over 50 years on their own initiative [34].

Despite the importance of understanding whether men with DUD have a higher prostate cancer incidence or mortality, research on this subject is very sparse. It has been shown that cannabis use is associated with higher incidence of prostate cancer [35], and that substance use disorder (SUD; alcohol included) is associated with adverse health outcomes in men with advanced stage prostate cancer [36, 37]. There is limited evidence regarding potential mechanisms linking substance use and prostate cancer, and substance-specific, biological mechanisms [35] as well as behavioral mechanisms such as healthcare seeking and treatment compliance [36] have been suggested in the scientific literature. Considering the high prevalence of unmet healthcare needs and delayed healthcare seeking among people with DUD, we hypothesized that DUD would be associated with an increased prostate cancer mortality, and more advanced cancer stage at the time of prostate cancer diagnosis. In the present study, we utilize nationwide population and healthcare registries with highly comprehensive individually linked data to examine prostate cancer incidence, mortality, and stage at the time of diagnosis among men with DUD compared to the general male population in Sweden, after adjusting for potential confounders, including SES.

\section{Methods}

\section{Data sources}

This retrospective cohort study was based on Swedish national register data. We constructed a dataset by linking data from the Swedish National Patient Register (NPR) for inpatient care (1964-2016) and outpatient care (2001-2016), the Swedish Cancer Register (1958-2016), the Total Population Register, the Swedish Cause of Death Register (1961-2016), the Swedish Prescribed Drug Register (2005-2016), the Crime Register (1973-2016), and the Suspicion Register (1995-2016). The national 10-digit civic registration number, which is assigned to each person in Sweden upon birth or immigration to the country, was used for register linkage. The national 10-digit civic registration number was replaced by a serial number to ensure the confidentiality of all individuals. The registers contain, e.g., individual-level data on age, sex, education, hospital admissions, dispensed drugs, and prostate cancer diagnoses on a nationwide basis, including the study population of men aged 50-75 years in Sweden.

Ethical approval for the study was obtained from the Regional Ethical Review Board in Lund (File Number 2012/795).

\section{Participants}

A total of 1,371,268 men in Sweden were 50-75 years of age on 1 January 1997 . The age range was motivated by the very low incidence of prostate cancer in men $<50$ years, and the estimated survival time in the study sample (the life expectancy among Swedish men is approximately 80 years). Those with a diagnosis of prostate cancer between 1 January 1991, and 31 December 1996 (i.e., with an earlier diagnosed cancer) were excluded ( $n=9736)$, leaving 1,361,532 men for inclusion in the study.

\section{Exposure}

Drug use disorders (DUD) were identified any time during the study period, and defined as a registration in the following registries: the NPR by relevant ICD-10 codes (F10-F19: mental and behavioral disorders due to psychoactive substance use, except those due to alcohol or tobacco); the Suspicion Register, which records suspected crimes related to drug use by codes 3070 (driving under the influence of drugs), 5010 (drug possession), 5011 (drug use), and 5012 (drug possession and use); and the Crime Register, which records convictions by references to laws covering narcotics (law 1968:64, paragraph 1, point 6) and drug-related driving offenses (law 1951:649, paragraph 4, subsection 2 and paragraph 4A, subsection 2). DUD was also identified in individuals (excluding any other cancer patients) in the Prescribed Drug Register who had filled prescriptions for hypnotics and sedatives (Anatomical Therapeutic Chemical [ATC] Classification System N05C and N05BA) or opioids (ATC: N02A) in average dosages of more than four defined daily doses a day for 12 months.

\section{Outcome variables}

Incident prostate cancer was defined as a diagnosis of prostate cancer according to the 7 th revision of the International Classification of Diseases (ICD-7 177) in the Swedish Cancer Register during the study period (1997-2016). 
The Swedish Cancer Register has transferred all cancer ICD codes into ICD-7.

Fatal prostate cancer was defined as a death attributed to prostate cancer as the primary cause according to the 10th revision of the ICD (ICD-10 C61) in the Swedish Cause of Death Register during the study period (1997-2016).

Prostate cancer stage 0-IV was obtained from the Swedish Cancer Register based on the TNM classification. TNM refers to Tumor (tumor characteristics, including size), Nodes (spread to nearby lymph nodes), and Metastases (spread to other parts of the body). Prior to statistical analysis, cancer stage was dichotomized into stage I-III and stage IV (i.e., metastasized prostate cancer). In the additional analysis, each cancer was only included once. Prostate cancer cases with tumor stage were included as outcomes.

\section{Covariates}

Age at entering the cohort was recorded as a continuous variable at 1 January 1997.

Educational attainment as of 1 January 1997 was categorized as $\leq 9$ years (partial or complete compulsory schooling), 10-11 years (partial or complete secondary schooling), and $12 \leq$ years (some or completed college and/or university studies). Prior to the statistical analysis, educational attainment was dichotomized into " $<12$ years" and " $12 \leq$ years."

Social welfare, received from social services, was defined as Yes (received) and No (not received).

Marital status as of 1 January 1997 was classified as mar$\mathrm{ried} /$ cohabiting, unmarried, divorced, or widowed. Prior to the statistical analysis, marital status was dichotomized into "married/cohabiting" vs. "not married/cohabiting" (including all unmarried, divorced, and widowed men).

Region of residence was categorized as "large city," "southern Sweden," and "northern Sweden." Prior to statistical analysis, region of residence was recoded into "large city" and "small city/countryside" from the original categories. Large cities were defined as one of the three largest cities in Sweden (Stockholm, Gothenburg, and Malmö), and "southern Sweden" and "northern Sweden" were recoded into "small city/countryside."

Immigrant status was defined as Yes (born outside Sweden) and No (born in Sweden).

The covariates education and social welfare were selected to capture SES, marital status was a proxy variable for social support and presumed healthcare seeking, region captures proximity to healthcare and immigrant status captures health literacy.

Chronic obstructive pulmonary disease (COPD) was used as a proxy variable for smoking and was identified according to ICD-10 diagnosis codes J40-J47.

Alcohol use disorder was identified according to ICD-10 F10 and K70 during the study period.

\section{Statistical analysis}

We used Cox regression models to estimate hazard ratios (HRs) with a 95\% confidence interval (CI) to test for the association between DUD and incident prostate cancer, fatal prostate cancer, and cancer stage at diagnosis. The men in the cohort were followed up from 1 January 1997 to the first prostate cancer diagnosis, death, migration from Sweden, or 31 December 2016. We used three models: Model 1 was unadjusted; Model 2 was adjusted for age, educational attainment, social welfare, marital status, region of residence, and immigrant status. Model 3 was additionally adjusted for comorbidities (COPD, alcohol use disorder). The proportional hazard assumptions were checked by plotting the incidence rates over time and calculating Schoenfeld (partial) residuals, and no substantial departures from these assumptions were found.

All statistical analyses were performed using SAS version 9.4 (SAS Institute Inc. Cary, NC, USA). All statistical tests were 2 -sided and used an $\alpha$-level of 0.05 .

\section{Secondary analyses}

A secondary analysis was conducted that repeated the main analyses after restricting the follow-up period to 2003-2016 to enable more complete outpatient ascertainment of DUD prior to prostate cancer diagnosis, since the NPR for outpatient care started in 2001. This study population was 1,493,595.

Another secondary analysis was conducted where we examined the association between DUD and prostate cancer mortality, while restricting to cancer stages I-III and adjusting for cancer stage.

\section{Results}

\section{Baseline characteristics}

The study population included 1,361,532 men aged 50-75 years in 1 January 1997 . The average follow-up time was $15.2 \pm 5.6$ years, with the mean follow-up time for men with and without DUD being 10.1 years and 15.8 years, respectively. The majority $(52.2 \%)$ had 9 years or less of education, $3.1 \%$ had received social welfare, $72.6 \%$ were married/cohabiting, $40.4 \%$ were living in large cities, and $21.8 \%$ were born outside Sweden (Table 1). DUD was identified in $0.7 \%(n=9,259)$. Compared with men without DUD, those with DUD were younger, less likely to be married/cohabiting, and more likely to be born in Sweden, live in large cities, receive social welfare, and/ 
Table 1 Population and number of events of incident and fatal prostate cancer

\begin{tabular}{|c|c|c|c|c|c|c|}
\hline & \multicolumn{2}{|c|}{ Total population } & \multicolumn{2}{|c|}{ Incident prostate cancer } & \multicolumn{2}{|c|}{$\begin{array}{l}\text { Fatal prostate } \\
\text { cancer }\end{array}$} \\
\hline & No & $\%$ & No & $\%$ & No & $\%$ \\
\hline \multicolumn{7}{|l|}{ Drug use disorders (DUD) } \\
\hline Non & $1,352,273$ & 99.3 & 129,772 & 99.3 & 26,380 & 99.1 \\
\hline Yes & 9259 & 0.7 & 891 & 0.7 & 236 & 0.9 \\
\hline \multicolumn{7}{|l|}{ Age groups (years) } \\
\hline $50-59$ & 683,095 & 50.2 & 58,322 & 44.6 & 5174 & 19.4 \\
\hline $60-69$ & 446,555 & 32.8 & 49,193 & 37.6 & 11,432 & 43.0 \\
\hline $70-75$ & 231,882 & 17.0 & 23,148 & 17.7 & 10,010 & 37.6 \\
\hline \multicolumn{7}{|l|}{ Educational attainment } \\
\hline$\leq 9$ years & 710,213 & 52.2 & 54,767 & 41.9 & 13,557 & 50.9 \\
\hline $10-11$ years & 243,740 & 17.9 & 26,496 & 20.3 & 5049 & 19.0 \\
\hline $12 \leq$ years & 407,579 & 29.9 & 49,400 & 37.8 & 8010 & 30.1 \\
\hline \multicolumn{7}{|l|}{ Social welfare } \\
\hline Non & $1,319,822$ & 96.9 & 128,052 & 98.0 & 26,138 & 98.2 \\
\hline Yes & 41,710 & 3.1 & 2611 & 2.0 & 478 & 1.8 \\
\hline \multicolumn{7}{|l|}{ Marital status } \\
\hline Married/cohabiting & 988,709 & 72.6 & 96,819 & 74.1 & 19,112 & 71.8 \\
\hline Not married/cohabiting & 372,823 & 27.4 & 33,844 & 25.9 & 7504 & 28.2 \\
\hline \multicolumn{7}{|l|}{ Region of residence } \\
\hline Large city & 549,566 & 40.4 & 63,164 & 48.3 & 11,610 & 43.6 \\
\hline Southern Sweden & 404,145 & 29.7 & 44,715 & 34.2 & 9502 & 35.7 \\
\hline Northern Sweden & 407,821 & 30.0 & 22,784 & 17.4 & 5504 & 20.7 \\
\hline \multicolumn{7}{|l|}{ Immigrant status } \\
\hline Born in Sweden & $1,064,951$ & 78.2 & 119,511 & 91.5 & 24,543 & 92.2 \\
\hline Born in other countries & 296,581 & 21.8 & 11,152 & 8.5 & 2073 & 7.8 \\
\hline \multicolumn{7}{|l|}{ COPD } \\
\hline Non & $1,261,964$ & 92.7 & 120,428 & 92.2 & 25,015 & 94.0 \\
\hline Yes & 99,568 & 7.3 & 10,235 & 7.8 & 1601 & 6.0 \\
\hline \multicolumn{7}{|l|}{ Alcohol use disorder } \\
\hline Non & $1,312,518$ & 96.4 & 127,034 & 97.2 & 26,017 & 97.7 \\
\hline Yes & 49,014 & 3.6 & 3629 & 2.8 & 599 & 2.3 \\
\hline All & $1,361,532$ & & 130,663 & & 26,616 & \\
\hline
\end{tabular}

$C O P D$ chronic obstructive pulmonary disease or have COPD or alcohol use disorder (Supplementary Table 1).

\section{Incident prostate cancer and DUD}

In the study population, $9.6 \%(n=130,663)$ were diagnosed with prostate cancer. We found no association between DUD and prostate cancer incidence in the univariate analysis (Model 1), nor in the multivariate analysis adjusted for age, educational attainment, social welfare, marital status, region of residence, and immigrant status (Model 2) (Table 2). However, in the multivariate analysis that adjusted for the covariates mentioned above as well as COPD and alcohol use disorder (Model 3), DUD was associated with a slightly increased risk of prostate cancer ( $\mathrm{HR}=1.07,95 \%$
CI 1.00-1.14, $p=0.048)$. In Model 3, prostate cancer was associated with higher age ( $\mathrm{HR}=1.41,95 \% \mathrm{CI} 1.40-1.42)$, residence in larger cities (HR $=1.27,95 \%$ CI $1.25-1.28)$, and COPD (HR $=1.04,95 \%$ CI 1.02-1.06). Factors associated with lower risk of prostate cancer included educational attainment $<12$ years ( $\mathrm{HR}=0.82,95 \% \mathrm{CI} 0.81-0.82)$, receipt of social welfare (HR $=0.91,95 \%$ CI $0.88-0.95)$, not being married/cohabiting ( $\mathrm{HR}=0.94,95 \% \mathrm{CI} 0.93-0.95)$, being born outside Sweden (HR $=0.32$, 95\% CI 0.31-0.32), and alcohol use disorder (HR $=0.86,95 \%$ CI $0.83-0.89)$.

\section{Fatal prostate cancer and DUD}

In the study population, $2.0 \%(n=26,616)$ died of prostate cancer during the study period. We found an association 
between DUD and fatal prostate cancer in the univariate analysis (Model 1) ( $\mathrm{HR}=1.38,95 \%$ CI 1.22-1.57), which persisted and increased slightly after adjustment for age, educational attainment, social welfare, marital status, region of residence, and immigrant status in Model 2 ( $\mathrm{HR}=1.52,95 \%$ CI 1.34-1.73), and further adjustment for COPD and alcohol use disorder in Model 3 (HR $=1.59,95 \%$ CI 1.40-1.82) (Table 3). In Model 3, fatal prostate cancer was associated with increasing age ( $\mathrm{HR}=3.12,95 \%$ CI $3.07-3.17)$, receipt of social welfare ( $\mathrm{HR}=1.20,95 \% \mathrm{CI} 1.09-1.31)$, not being married/cohabiting ( $\mathrm{HR}=1.17,95 \% \mathrm{CI} 1.14-1.21)$, and residence in a large city $(\mathrm{HR}=1.07,95 \%$ CI $1.04-1.10)$. Lower risk of fatal prostate cancer was associated with being born outside Sweden (HR $=0.26$, 95\% CI 0.25-0.27), COPD $(\mathrm{HR}=0.70,95 \% \mathrm{CI} 0.67-0.74)$, and alcohol use disorder $(\mathrm{HR}=0.90,95 \%$ CI $0.82-0.97)$. No association was found between educational attainment and fatal prostate cancer.

\section{Prostate cancer stage and DUD}

After exclusion of men without data on TNM stage, $1,240,922$ individuals remained for the analysis. We found no association between DUD and tumor stage at prostate cancer diagnosis, when adjusting for age, educational attainment, social welfare, marital status, region of residence, immigrant status, COPD, and alcohol use disorder (Table 4).

\section{Secondary analyses}

A secondary analysis of incident and fatal prostate cancer with follow-up during 2003-2016 showed that DUD was significantly associated with fatal prostate cancer (HR 2.00; 95\% CI 1.71-2.33; $p<0.001$ ), when adjusting for age, educational attainment, social welfare, marital status, region of residence, immigrant status, COPD, and alcohol use disorder (Supplementary Table 2).

In a secondary analysis of fatal prostate cancer while restricting to cancer stages I-III and adjusting for cancer stage, DUD was significantly associated with fatal prostate cancer (HR 1.48; 95\% CI 1.30-1.69; $p<0.001$ ) (Supplementary Table 3 ).

\section{Discussion}

To our knowledge, this is the first population-based study of prostate cancer incidence, mortality, and stage at diagnosis among men with DUD. We identified DUD as a strong predictor for fatal prostate cancer, which supported our hypothesis regarding mortality, whereas DUD was associated with only a slightly increased risk of incident prostate cancer. Our findings were somewhat similar to the retrospective, longitudinal cohort studies by Chhatre et al. and Jayadevappa 


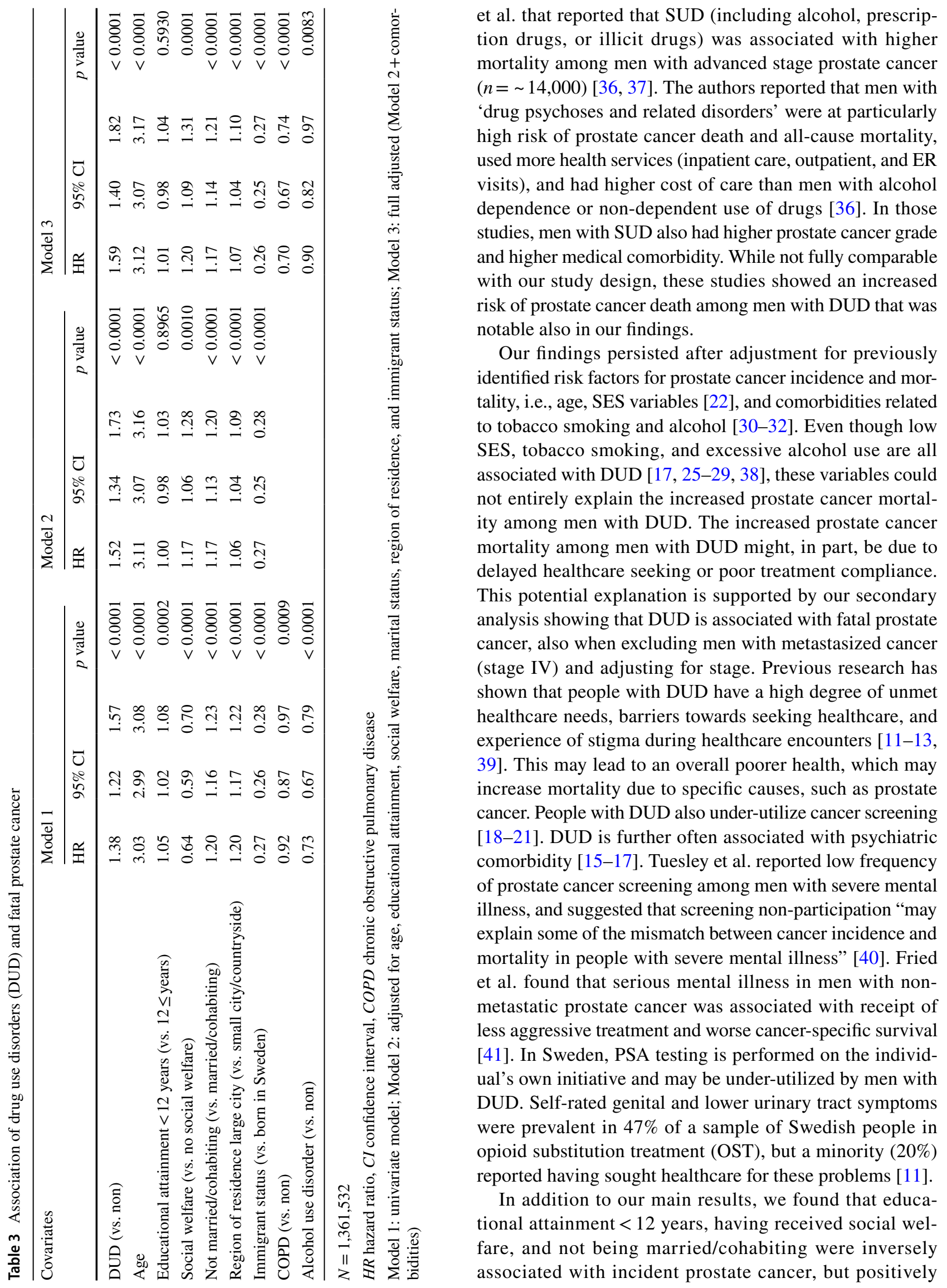


Table 4 Association of drug use disorders (DUD) and prostate cancer stage at time of diagnosis among men with incident prostate cancer

\begin{tabular}{|c|c|c|c|c|c|c|c|c|}
\hline \multirow[t]{2}{*}{ Covariates } & \multicolumn{4}{|c|}{$\begin{array}{l}\text { Prostate cancer stage I-III (vs. no prostate } \\
\text { cancer and prostate cancer stage IV) }\end{array}$} & \multicolumn{4}{|c|}{$\begin{array}{l}\text { Prostate cancer stage IV (vs. no pros- } \\
\text { tate cancer and prostate cancer stage } \\
\text { I-III) }\end{array}$} \\
\hline & HR* & $95 \% \mathrm{CI}$ & & $p$ value & $\mathrm{HR}^{*}$ & $95 \% \mathrm{CI}$ & & $p$ value \\
\hline DUD (vs. non) & 1.00 & 0.78 & 1.27 & 0.9814 & 0.79 & 0.11 & 5.72 & 0.8119 \\
\hline
\end{tabular}

$N 1,240,922$. Cases of prostate cancer: 10,378

$H R$ hazard ratio, $C I$ confidence interval, $C O P D$ chronic obstructive pulmonary disease

*Full adjusted (for age, educational attainment, social welfare, marital status, region of residence, immigrant status, COPD, and alcohol use disorder) (social welfare, marital status) or non-significantly (educational attainment) associated with fatal prostate cancer. These findings are in line with the previous research identifying an association between high SES and higher incidence of low- to moderate-risk prostate cancer, possibly related to increased screening $[42,43]$; whereas low SES, including income, marital status, and educational attainment, has been associated with poorer prostate cancer outcomes [44-47]. Being a resident in a large city was associated with both incident and fatal prostate cancer, while being born outside Sweden was inversely associated with both incident and fatal prostate cancer. The latter finding was consistent with the results from several studies showing lower prostate cancer incidence and mortality among immigrants in, e.g., Australia, Germany, and Canada [48-50]. While incident prostate cancer was associated with COPD but inversely associated with alcohol use disorder, both COPD and alcohol use disorder were inversely associated with fatal prostate cancer, which might be explained by high fatality rates related to COPD and excessive alcohol use, such as increased mortality in liver diseases and other alcohol-related diseases. It is also notable that COPD is not equivalent to tobacco smoking, and some people diagnosed with COPD might be more likely to quit smoking than people without COPD. This could potentially affect the risk of prostate cancer.

Our finding that men with DUD were at high risk for fatal prostate cancer has important clinical implications. Improved access to and retention in OST has led to an aging population of patients with treated opioid dependence [51], and thus reaching ages when prostate cancer is more common. Our findings suggest that healthcare professionals and policy-makers need to be aware of the increased health risks in men with DUD in order to improve prostate cancer screening, treatment, and survival in this population. Future research regarding healthcare seeking barriers and prostate cancer treatment compliance among men with DUD is needed in order to decrease these health inequities.

\section{Strengths and limitations}

The nationwide data used in this study were obtained from several high-quality national registers. The Swedish Cancer Register has almost $100 \%$ validity and coverage [52-54], and $85-95 \%$ of the diagnoses in the NPR are valid [55]. The Swedish Total Population Register is nearly $100 \%$ complete [56, 57].

The broad definition of DUD applied in this study, ranging from a diagnosis in the NPR to a registration of drug possession in the Suspicion Register, has been used in several previous studies [7, 58]. Although this definition may include some men with sporadic drug use rather than DUD, our intention was to include men with DUD that had not been noted by the healthcare system and registered in the NPR. According to a survey made in 2017 by the Swedish Council for Information on Alcohol and Other Drugs, an estimated $1.8 \%$ of the Swedish adult population reported drug use [59]. The $0.7 \%$ prevalence of DUD from our register data is lower than the survey data, which likely is due to the high age (50-75 years) at inclusion in our study.

The association between DUD and fatal prostate cancer had a higher HR in the secondary analysis beginning in 2003 than in the main analysis (HR 2.00 vs. HR 1.59). This might be explained by some men with DUD being misclassified as not having DUD in the main analysis (before outpatient data were available), thus resulting in underestimation of the HR for fatal prostate cancer associated with DUD.

Data on types of substances used, quantification of DUD, or addiction treatment, would have allowed for more refined analyses. Severe DUD (compared to occasional, recreational drug use) might be associated with higher cancer mortality due to lower healthcare seeking and less adequate preventive healthcare, but could also be associated with lower cancer mortality due to premature, drug-related death [3,4]. Given the limitations of the registers used, we did not have access to such data on a total-population level. Main drug and DUD severity in relation to prostate cancer incidence and mortality would be useful to examine in future research. Such 
research could also assess potential biological mechanisms behind use of specific drugs and prostate cancer incidence and mortality. Information on receipt of PSA tests, PSA level at diagnosis, prostate cancer grade, and time between diagnosis and treatment was also unavailable for our analyses. Although we found no association between DUD and prostate cancer stage, it is still possible that DUD is associated with more advanced disease at diagnosis, which is important to assess further in future studies. Our findings on prostate cancer stage at diagnosis should be interpreted with caution since data on cancer stage wer available only in $7.9 \%$ of the sample with incident prostate cancer.

\section{Conclusion}

In this large national cohort of men, we found that DUD was associated with slightly higher prostate cancer incidence and substantially higher prostate cancer mortality. Our hypothesis that DUD would be associated with an increased prostate cancer mortality was supported by the analyses, while the hypothesis that DUD would be associated with higher prostate cancer stage at the time of diagnosis was not. Our findings should raise attention among clinicians and health policy-makers towards a disadvantaged group of men in need of easily accessible prostate cancer evaluation and treatment.

Supplementary Information The online version contains supplementary material available at https://doi.org/10.1007/s10552-021-01513-2.

Authors contributions DD and KS were responsible for the research idea and study design. XL conducted the data retrieval and statistical analyses. All authors contributed to the interpretation of the results, and manuscript writing.

Funding Open access funding provided by Lund University. This work was supported by the National Institute on Drug Abuse at the National Institutes of Health (R01DA030005); and from the Swedish Research Council to Jan Sundquist (2020-01175) and to Kristina Sundquist (2018-02400); ALF research grant ("Yngre ALF"), Region Skåne/Lund University, Sweden; and research funding granted from the Primary Healthcare Management in Region Skåne (Sweden) to Disa Dahlman. The funding agencies had no role in the design and conduct of the study; in the collection, analysis, and interpretation of the data; or in the preparation, review, or approval of the manuscript.

Data availability The data used to support the findings of this study are restricted by the Swedish authorities, in order to protect people's privacy. Please refer to Kristina Sundquist for questions on data availability.

\section{Declarations}

Conflict of interest All authors (Disa Dahlman, Xinjun Li, Casey Crump, Jan Sundquist, and Kristina Sundquist) declare that they have no conflict of interest.

Code availability Not applicable.

Ethical approval All procedures in the study were in accordance with the ethical standards of the institutional and/or national research committee and with the 1964 Helsinki declaration and its later amendments or comparable ethical standards. Ethical approval for the study was obtained from the Regional Ethical Review Board in Lund.

Consent to participate Consent to participate was not obtained from the individuals in the registers used in this study.

Consent for publication Consent for publication was not obtained from the individuals in the registers used in this study.

Open Access This article is licensed under a Creative Commons Attribution 4.0 International License, which permits use, sharing, adaptation, distribution and reproduction in any medium or format, as long as you give appropriate credit to the original author(s) and the source, provide a link to the Creative Commons licence, and indicate if changes were made. The images or other third party material in this article are included in the article's Creative Commons licence, unless indicated otherwise in a credit line to the material. If material is not included in the article's Creative Commons licence and your intended use is not permitted by statutory regulation or exceeds the permitted use, you will need to obtain permission directly from the copyright holder. To view a copy of this licence, visit http://creativecommons.org/licenses/by/4.0/.

\section{References}

1. Bray F, Ferlay J, Soerjomataram I, Siegel RL, Torre LA, Jemal A (2018) Global cancer statistics 2018: GLOBOCAN estimates of incidence and mortality worldwide for 36 cancers in 185 countries. CA Cancer J Clin 68(6):394-424

2. Rawla P (2019) Epidemiology of prostate cancer. World J Oncol 10(2):63-89

3. Nyhlén A, Fridell M, Hesse M, Krantz P (2011) Causes of premature mortality in Swedish drug abusers: a prospective longitudinal study 1970-2006. J Forensic Leg Med 18(2):66-72

4. von Greiff N, Skogens L, Berlin M, Bergmark A (2018) Mortality and cause of death-a 30-year follow-up of substance misusers in Sweden. Subst Use Misuse 53(12):2043-2051

5. Gao L, Robertson JR, Bird SM (2019) Non drug-related and opioid-specific causes of 3262 deaths in Scotland's methadone-prescription clients, 2009-2015. Drug Alcohol Depend 197:262-270

6. Randall D, Degenhardt L, Vajdic CM et al (2011) Increasing cancer mortality among opioid-dependent persons in Australia: a new public health challenge for a disadvantaged population. Aust N Z J Public Health 35(3):220-225

7. Dahlman D, Magnusson H, Li X, Sundquist J (2020) Sundquist K (2020) Drug use disorder and risk of incident and fatal breast cancer: a nationwide epidemiological study. Breast Cancer Res Treat. https://doi.org/10.1007/s10549-020-05998-4

8. Mathers BM, Degenhardt L, Phillips B et al (2007) Reference Group to the UN on HIV and injecting drug use (2008) Global 
epidemiology of injecting drug use and HIV among people who inject drugs: a systematic review. Lancet 372(9651):1733-1745

9. Hallinan R, Byrne A, Amin J, Dore GJ (2005) Hepatitis C virus prevalence and outcomes among injecting drug users on opioid replacement therapy. J Gastroenterol Hepatol 20:1082-1086

10. Islam MM, Taylor A, Smyth C, Day CA (2013) General health of opioid substitution therapy clients. Intern Med J 43:1335-1358

11. Troberg K, Hakansson A, Dahlman D (2019) Self-rated physical health and unmet healthcare needs among swedish patients in opioid substitution treatment. J Addict 2019:7942145

12. Powelson E, Lorvick J, Lutnick A, Wenger L, Klausner J, Kral AH (2014) Unmet healthcare need among women who use methamphetamine in San Francisco. Subst Use Misuse 49(3):243-252

13. Chitwood DD, Comerford M, McCoy HV (2002) Satisfaction with access to health care among injection drug users, other drug users, and nonusers. J Behav Health Serv Res 29(2):189-197

14. Dahlman D, Ekefäll M, Garpenhag L (2020) Health literacy among swedish patients in opioid substitution treatment: a mixedmethods study. Drug Alcohol Depend 214:108186

15. Savant JD, Barry DT, Cutter CJ et al (2013) Prevalence of mood and substance use disorders among patients seeking primary care office-based buprenorphine/naloxone treatment. Drug Alcohol Depend 127(1-3):243-247

16. Jones CM, McCance-Katz EF (2019) Co-occurring substance use and mental disorders among adults with opioid use disorder. Drug Alcohol Depend 197:78-82

17. Öhlin L, Fridell M, Nyhlén A (2015) Buprenorphine maintenance program with contracted work/education and low tolerance for non-prescribed drug use: a cohort study of outcome for women and men after seven years. BMC Psychiatry 15:56

18. Jensen LF, Pedersen AF, Bech BH, Andersen B, Vedsted P (2016) Psychiatric morbidity and non-participation in breast cancer screening. Breast 25:38-44

19. Spithoff S, Kiran T, Khuu W et al (2019) Quality of primary care among individuals receiving treatment for opioid use disorder. Can Fam Physician 65:343-351

20. Kricker A, Burns L, Goumas C, Armstrong BK (2013) Cervical screening, high-grade squamous lesions, and cervical cancer in illicit drug users. Cancer Causes Control 24(7):1449-1457

21. Tilley DM, Hristov S, Templeton DJ, Sharp NC, O'Connor CC (2012) Cervical cancer screening and abnormalities among women in a residential drug-rehabilitation program. Aust J Prim Health 18(4):266-267

22. Coughlin SS (2020) A review of social determinants of prostate cancer risk, stage, and survival. Prostate Int 8(2):49-54

23. Hiscock R, Bauld L, Amos A, Fidler JA, Munafò M (2012) Socioeconomic status and smoking: a review. Ann N Y Acad Sci 1248:107-123

24. Collins SE (2016) Associations between socioeconomic factors and alcohol outcomes. Alcohol Res 38(1):83-94

25. Reece A (2007) Lifetime prevalence of cervical neoplasia in addicted and medical patients. Aust N Z J Obstet Gynaecol 47(5):419-423

26. Nolan S, Klimas J, Wood E (2016) Alcohol use in opioid agonist treatment. Addict Sci Clin Pract 11(1):17

27. Campbell BK, Le T, Gubner NR, Guydish J (2019) Health risk perceptions and reasons for use of tobacco products among clients in addictions treatment. Addict Behav 91:149-155

28. Zirakzadeh A, Schuman C, Stauter E, Hays JT, Ebbert JO (2013) Cigarette smoking in methadone maintained patients: an up-todate review. Curr Drug Abuse Rev 6:77-84

29. Bowman J, Wiggers J, Colyvas K, Wye P, Walsh RA, Bartlem K (2012) Smoking cessation among Australian methadone clients: prevalence, characteristics and a need for action. Drug Alcohol Rev 31(4):507-513
30. Zhao J, Stockwell T, Roemer A, Chikritzhs T (2016) Is alcohol consumption a risk factor for prostate cancer? A systematic review and meta-analysis. BMC Cancer 16(1):845

31. Darcey E, Boyle T (2018) Tobacco smoking and survival after a prostate cancer diagnosis: a systematic review and meta-analysis. Cancer Treat Rev 70:30-40

32. Hong S, Khil H, Lee DH, Keum N, Giovannucci EL (2020) Alcohol consumption and the risk of prostate cancer: a doseresponse meta-analysis. Nutrients 12(8):2188

33. Anell A, Glenngard AH, Merkur S (2012) Sweden: health system review. Health Syst Transit 14:1-159

34. Socialstyrelsen (2018) Screening för prostatacancer. Rekommendation och bedömningsunderlag. [Swedish] https://www. socialstyrelsen.se/globalassets/sharepoint-dokument/artikelkat alog/nationella-screeningprogram/2018-10-15.pdf. Accessed 16 Nov 2020

35. Skeldon SC, Goldenberg SL (2014) Urological complications of illicit drug use. Nat Rev Urol 11(3):169-177

36. Chhatre S, Metzger DS, Malkowicz SB, Woody G, Jayadevappa R (2014) Substance use disorder and its effects on outcomes in men with advanced-stage prostate cancer. Cancer 120(21):3338-3345

37. Jayadevappa R, Chhatre S (2016) Association between age, substance use, and outcomes in Medicare enrollees with prostate cancer. J Geriatr Oncol 7(6):444-452

38. Centralförbundet för alkohol- och narkotikaupplysning (2002) Narkotikamissbruk och marginalisering MAX-projektet, slutrapport [Swedish]. https://wwwcanse.cdn.triggerfish.cloud/ uploads/2020/01/can-rapportserie-65-narkotikamissbruk-ochmarginalisering-max-projektet-slutrapport.pdf. Accessed 19 Dec 2020

39. Miller-Lloyd L, Landry J, Macmadu A, Allard I, Waxman M (2020) Barriers to healthcare for people who inject drugs: a survey at a syringe exchange program. Subst Use Misuse 55(6):896-899

40. Tuesley KM, Jordan SJ, Siskind DJ, Kendall BJ, Kisely S (2019) Colorectal, cervical and prostate cancer screening in Australians with severe mental illness: Retrospective nation-wide cohort study. Aust N Z J Psychiatry 53(6):550-558

41. Fried DA, Sadeghi-Nejad H, Gu D et al (2019) Impact of serious mental illness on the treatment and mortality of older patients with locoregional high-grade (nonmetastatic) prostate cancer: retrospective cohort analysis of 49985 SEER-Medicare patients diagnosed between 2006 and 2013. Cancer Med 8(5):2612-2622

42. Cheng I, Witte JS, McClure LA et al (2009) Socioeconomic status and prostate cancer incidence and mortality rates among the diverse population of California. Cancer Causes Control 20(8):1431-1440

43. Kilpeläinen TP, Talala K, Raitanen J et al (2016) Prostate cancer and socioeconomic status in the finnish randomized study of screening for prostate cancer. Am J Epidemiol 184(10):720-731

44. Li X, Sundquist K, Sundquist J (2012) Neighborhood deprivation and prostate cancer mortality: a multilevel analysis from Sweden. Prostate Cancer Prostatic Dis 15(2):128-134

45. Aizer AA, Chen MH, McCarthy EP et al (2013) Marital status and survival in patients with cancer. J Clin Oncol 31(31):3869-3876

46. Li ML, Lin J, Hou JG et al (2014) Environmental and psychosocial factors related to prostate cancer risk in the Chinese population: a case-control study. Biomed Environ Sci 27(9):707-717

47. DeRouen MC, Schupp CW, Koo J et al (2018) Impact of individual and neighborhood factors on disparities in prostate cancer survival. Cancer Epidemiol 53:1-11

48. Feletto E, Sitas F (2015) Quantifying disparities in cancer incidence and mortality of Australian residents of New South Wales (NSW) by place of birth: an ecological study. BMC Public Health $15: 823$ 
49. Kaucher S, Kajüter H, Becher H, Winkler V (2018) Cancer incidence and mortality among ethnic german migrants from the former soviet union. Front Oncol 8:378

50. McDonald JT, Farnworth M, Liu Z (2017) Cancer and the healthy immigrant effect: a statistical analysis of cancer diagnosis using a linked Census-cancer registry administrative database. BMC Public Health 17(1):296

51. Han B, Polydorou S, Ferris R, Blaum CS, Ross S, McNeely J (2015) Demographic trends of adults in new york city opioid treatment programs-an aging population. Subst Use Misuse 50(13):1660-1667

52. Mattsson B, Wallgren A (1984) Completeness of the swedish cancer register. non-notified cancer cases recorded on death certificates in 1978. Acta Radiol Oncol 23:305-313

53. Barlow L, Westergren K, Holmberg L, Talbäck M (2009) The completeness of the swedish cancer register: a sample survey for year 1998. Acta Oncol 48:27-33

54. Socialstyrelsen (2012) Cancer Incidence in Sweden 2011. https:// www.socialstyrelsen.se/globalassets/sharepoint-dokument/artik elkatalog/statistik/2012-12-19.pdf. Accessed 19 Dec 2020

55. Ludvigsson JF, Andersson E, Ekbom A et al (2011) External review and validation of the Swedish national inpatient register. BMC Public Health 11:450
56. Ahrens W, Pigeot I (eds). Use of disease registers. Handbook of epidemiology. 2005: Springer-Verlag, Berlin

57. SCB (2011) SCB-data för forskning 2011 [Microdata at Statistics Sweden for research purposes 2011]. http://www.su.se/polopoly_ fs/1.55468.1321514479!/SCB_data_for_forskare.pdf. Accessed 19 Dec 2020

58. Edwards AC, Ohlsson H, Sundquist J, Sundquist K, Kendler KS (2020) Socioeconomic sequelae of drug abuse in a Swedish national cohort. Drug Alcohol Depend 212:107990

59. Centralförbundet för alkohol- och narkotikaupplysning (2019) Drogutvecklingen i Sverige [Swedish]. https://wwwcanse.cdn. triggerfish.cloud/uploads/2020/01/can-rapport-180-drogutveck lingen-i-sverige-2019.pdf. Accessed 19 Dec 2020

Publisher's Note Springer Nature remains neutral with regard to jurisdictional claims in published maps and institutional affiliations. 